\title{
Aural Toileting and Dressing-Important Intervention Measures in the Management of Acute Suppurative Otitis Media
}

\author{
Kufre Roberts Iseh*, Stanley Baba Amutta, Abdullahi Mohammed, Daniel Aliyu, \\ Kingsley Osisi, Lawali Argungu Salihu, Silifat Oyewusi, Grace Iseh \\ Department of Otorhinolaryngology, Usmanu Danfodiyo University Teaching Hospital, Sokoto, Nigeria \\ Email: frobih@yahoo.com
}

Received 7 July 2014; revised 5 August 2014; accepted 1 September 2014

Copyright (C) 2014 by authors and Scientific Research Publishing Inc. This work is licensed under the Creative Commons Attribution International License (CC BY). http://creativecommons.org/licenses/by/4.0/

cC) (i) Open Access

\section{Abstract}

Background: Otitis media is one of the most common childhood infections, the leading cause of doctor's visit by children in ENT clinic. The acute form if not recognized early is commonly characterized by suppuration from the middle ear following perforation of the tympanic membrane otherwise referred to as acute suppurative otitis media (ASOM). If not adequately treated, it progresses to chronic suppurative otitis media with attendant challenges in management. Ceasation of ear discharge is an indication of resolution of disease. The objective of this study is to appraise the value of local ear suction toileting and dressing in the ceasation of ear discharge in acute suppurative otitis media. Materials and Method: Consecutive new cases of acute suppurative otitis media seen at the Ear, Nose and Throat clinic of a tertiary health centre in north western Nigeria were assessed for efficacy of aural toileting and dressing with antibioctic impregnated guaze in the treatment of acute suppurative otitis media and compared with patients with similar disease without aural toileting and dressing or dressing with normal saline soaked guaze in addition to systemic antibiotic and antihistamine medications. Ear toileting was done by suctioning the discharge with suction machine, and cleaning the external auditory canal with hydrogen peroxide and methylated spirit. They were then dressed with gauze impregnated with antibiotic ear drops daily until there was no more ear discharge. The period of ceasation of ear discharge in each group was assessed. Results: There were 39 patients with acute suppurative otitis media (ASOM). Eighteen were females $(46.2 \%)$ while 21 were males (53.8\%), giving $M: F$ ratio 1:2.1. Their ages ranged between 1 month and 45 years. About $36(92.3 \%)$ were children and out of this, $28(77.8 \%)$ were less than 5 years old. The average period of ceasation of discharge was 24 - 48 hours with those undergoing ear toileting and dressing but varied between 7 and 10 days with those without ear dressing or dressing with normal saline soaked guaze. This finding compelled us to stop the study

\footnotetext{
"Corresponding author.
}

How to cite this paper: Iseh, K.R., Amutta, S.B., Mohammed, A., Aliyu, D., Osisi, K., Salihu, L.A., Oyewusi, S. and Iseh, G. (2014) Aural Toileting and Dressing-Important Intervention Measures in the Management of Acute Suppurative Otitis Media. International Journal of Otolaryngology and Head \& Neck Surgery, 3, 233-238. 
on ethical grounds when this was carried out in the first 5 patients on each side of the study groups necessitating reversals of other groups to aural toileting and dressing with antibiotic impregnated guaze. Conclusion: Local ear toileting and dressing appear to show significant contribution to the early ceasation of ear discharge and are highly recommended not only for acute suppurative otitis media but also for all suppurative ear diseases.

\section{Keywords}

\section{Acute Suppurative Otitis Media, Ear Dressing, Ear Toileting}

\section{Introduction}

Otitis media is one of the most common childhood infections, the leading cause of doctor's visit by children in ENT clinic [1] [2]. More than two-thirds of children experience one or more attacks of acute otitis media by the age of 3 years and about half experience more than three episodes [3]. It is less common at school age [4]. Brobby reported that $50 \%-70 \%$ of children in Ghana had experienced an episode of acute otitis media (AOM) by their first birthday [5].

Acute otitis media (AOM) may be defined clinicopathologically as inflammation of the middle ear cleft of rapid onset and infective origin, associated with a middle ear effusion and a varied collection of clinical symptoms and signs [6]. The acute form if not recognized early is commonly characterized by suppuration from the middle ear following perforation of the tympanic membrane otherwise referred to as acute suppurative otitis media (ASOM). It is the commonest ear pathology in otorhinolaryngological (ORL) practice [7].

Before commencement of treatment for ASOM, it is ideal to take ear swab for microscopy, culture and sensitivity. The pattern of bacteriology varies from regions. In Western literature, Streptococcus pneumonia, Haemophilus influenza and Moraxella catarrhalis are widely reported in the USA, Canada, Colombia, Sweden and even Japan [8]-[12]. Some European studies found Haemophilus influenza to be the most common organism followed by Streptococcus pneumonia and Moraxella catarrhalis [9] [10]. However, in studies done in Nigeria, Staphylococcus aureus was the commonest organism cultured [7] [13] [14]. In Ghana, Brobby cultured Streptococcus pyogenes in patients who had suppuration from the middle ear within 7 days [15].

If there is intervention, there will be resolution of symptoms and no suppuration. However, when there is suppuration which may highlight reduction of pain, this brings the patients to the clinic. With antibiotic treatment, the infection most likely will resolve with ceasation of discharge over a varying period depending on the local bacterial culture and sensitivity to antibiotics.

Most patients who present to the clinic are assessed with ear swab for microscopy, culture and sensitivity. Although broad-spectrum antibiotics are given pending the outcome of the result, some of them may experience some form of ceasation of suppuration over a variable period of 72 hours to 1 week.

However, persistence of ear discharge, which may proceed to chronic suppurative otitis media which is a major disease burden recognized by World Health Organisation (WHO) [16] poses challenges in management because of its attendant complications. Ceasation of discharge is most desirable and it is an indicator of resolution of the disease which should be maintained as long as possible to encourage new membrane formation and sealing of the tympanic membrane. Lack of confidence in orthodox medicine, indifference and non-pragmatic approach perceived about health workers in our environment, poor compliance to antibiotic treatment, ignorance and poverty contribute significantly to persistence of ear discharge in most countries of sub-Saharan region and therefore promote chronicity.

In an attempt to introduce a more pragmatic approach in the treatment of acute suppurative otitis media, aural toileting and dressing, after ear swab was taken for microscopy, culture and sensitivity $(\mathrm{m} / \mathrm{c} / \mathrm{s})$, was introduced from the first visit in an ORL clinic to assess the effectiveness of ceasation of ear discharge following ASOM. The basis of this study is to justify the need for immediate otologic intervention in all suppurative ear disease and to reduce chronicity of ear discharge, infection and attendant complications.

\section{Materials and Method}

The study was carried out in the Ear, Nose and Throat (ENT) clinic of Usmanu Danfodiyo University Teaching 
Hospital, Sokoto, North Western Nigeria over 1 month period. The study was an interventional, hospital-based study.

Thirty nine consecutive patients were assessed for efficacy of ear toileting and antibiotic-impregnated ear dressing with those with ear dressing with normal saline or without ear dressing at all. They were all placed on oral broad-spectrum antibiotics and antihistamine. Acute suppurative otitis media in this study refers to ear discharge of less than 2 weeks duration [17].

Patients were stratified into 3 groups.

Group 1: Patients on broad-spectrum oral antibiotics, antihistamine, aural toileting with antibiotic-impregnated gauze dressing.

Group 2: Patients on broad-spectrum oral antibiotics, antihistamine with ear dressing with normal saline.

Group 3: Patients on broad-spectrum oral antibiotics, antihistamine with no ear dressing at all.

The consecutive patients were given numbers 1 to 3 as they appear in the clinic, not knowing the details of each group. Informed consent was obtained from parents/caregivers about the study and the findings were to be disclosed to them.

Aural toileting was carried out as follows:

The Physician or Nurse sits down and the patient or mother carrying the child is seated in a mummified position. With the use of a head mirror with a Bull's eye lamp to focus the light or a head light to focus light on the ear. The head of the patient was turned with the ear to be treated facing the Physician or Nurse. After ear swab was taken for microscopy culture and sensitivity, gentle suction of the ear discharge with suction catheter connected to a suction machine was carried out on the first visit regarded as day 1 . This was to be repeated on every day of discharge particularly if the discharge had filled the external auditory canal occluding the tympanic membrane. The suctioning should be carried out in such a way that injury should not be inflicted on the external auditory canal or further rupturing of the already perforated tympanic membrane should not occur. Then, the external auditory canal was mopped with gauze or cotton wool soaked with hydrogen peroxide $\left(\mathrm{H}_{2} \mathrm{O}_{2}\right)$ or methylated spirit attached to Jobson-Horne probe under direct vision.

Gauze impregnated with topical antibiotic such as ofloxacin or otomed (Fludrocortisone acetate-Neomycin-Polymycin B sulphate) was used for ear dressing with the aid of aural dressing forceps under direct vision. Judgement as to ceasation of ear discharge was when the gauze inserted into the external auditory canal remained dry and appeared white with no evidence of discharge from the dressing for the previous 24 hours. The age, sex, diagnosis, types of dressing compared with period of ceasation of ear discharge were all recorded and data analysed through simple descriptive statistics.

\section{Results}

Table 1 shows that there were 39 patients with acute suppurative otitis media. Eighteen were females (46.2\%) while 21 were males (53.8\%), giving M:F ratio of 1.2:1.

Their ages ranged between 1 month and 45 years. About 36 (92.3\%) were children and out of this, 28 (77.8\%) were less than 5 years old.

There was minimal ear discharge after 24 hours (day 2) following the first (day 1) aural toileting with suctioning and dressing in all patients of the first group and complete ceasation by 48 hours (day 3) requiring no further ear toileting or dressing as shown in Table 2. However, ear discharge persisted in other groups for a va-

\begin{tabular}{|c|c|}
\hline Age (years) & $\mathrm{n}=39(100 \%)$ \\
\hline$<5$ years & 28 (71.79\%) \\
\hline 5 - 18 years & $8(20.51 \%)$ \\
\hline 18 - 27 years & $0(0 \%)$ \\
\hline 28 - 37 years & $0(0 \%)$ \\
\hline$>35$ years & $3(7.7 \%)$ \\
\hline \multicolumn{2}{|l|}{ Sex } \\
\hline Male & $21(53.8 \%)$ \\
\hline Female & $18(46.2 \%)$ \\
\hline
\end{tabular}


Table 2. Treatment options and recovery status.

\begin{tabular}{|c|c|c|c|c|}
\hline \multicolumn{2}{|c|}{ Variable } & \multicolumn{3}{|c|}{ Groups } \\
\hline & & Group $1 \mathrm{n}=13(100 \%)$ & Group 2 n = 13 (100\%) & Group 3 n = 13 (100\%) \\
\hline \multirow{2}{*}{$<48$ hours } & Resolved & $13(100 \%)$ & $0(0 \%)$ & $0(0 \%)$ \\
\hline & Unresolved & $0(0 \%)$ & $13(100 \%)$ & $13(100 \%)$ \\
\hline \multirow{2}{*}{3 - 5 days } & Resolved & $13(100 \%)$ & $0(0 \%)$ & $0(0 \%)$ \\
\hline & Unresolved & $0(0 \%)$ & $13(100 \%)$ & $13(100 \%)$ \\
\hline \multirow{2}{*}{6 - 7 days } & Resolved & $13(100 \%)$ & $0(0 \%)$ & $0(0 \%)$ \\
\hline & Unresolved & $0(0 \%)$ & $13(100 \%)$ & $13(100 \%)$ \\
\hline \multirow{2}{*}{7 - 9 days } & Resolved & $13(100 \%)$ & $\begin{array}{l}13(100 \%) \text { when reverted to } \\
\text { group } 1 \text { modality of treatment }\end{array}$ & $\begin{array}{l}13(100 \%) \text { when reverted to } \\
\text { group } 1 \text { modality of treatment }\end{array}$ \\
\hline & Unresolved & $0(0 \%)$ & $0(0 \%)$ & $0(0 \%)$ \\
\hline
\end{tabular}

N.B. No statistical test could be performed on this table because more than $50 \%$ of the cells had no value (i.e. zero).

riable minimum period of 5 to 7 days as shown in Table 2. This study was suspended on ethical grounds when there was significant difference in response to the intervention measure in one group within 24 to 48 hours when compared to other groups.

As a result of this finding, all others in groups 2 and 3 (i.e. 26 patients) who were still having ear discharge were reverted back to the first group modality of treatment which was suction toileting and ear dressing. Subsequently this was the modality adopted in the clinic for all cases of acute suppurative otitis media. When the other groups were reverted to aural toileting and dressing, the ear discharge ceased within 24 - 48 hours as seen in days 7 - 9 in Table 2.

\section{Discussion}

Acute suppurative otitis media may resolve with antibiotic, nasal decongestant and antihistamine treatment with varying periods of ceasation of ear discharge when aural toileting and dressing is not carried out. In a study done in Sokoto, otorrhoea was the commonest presenting symptom of ASOM [7]. It is the ear discharge that usually necessitates referral to our ENT clinic. Therefore, ceasation of ear discharge was the only symptom assessed in this study.

Aural toileting has been reported widely in chronic suppurative otitis media and only very few people have talked about it for treatment of ASOM [18]. There is general agreement that aural toileting must be part of the standard treatment for chronic suppurative otitis media [18]. Cleaning the ear of mucoid discharge could reduce, even if temporarily, the quantity of infected material from the middle ear and could facilitate middle ear penetration of topical anti-microbial [18]. Eason et al. [19] observed that 50\% of 26 ears of school children studied became dry with aural toileting alone. However, during another study, he found that $58 \%$ of 41 ears treated with topical antibiotics (framycetin-gramicidin-dexamthasone), aural toileting became dry [19]. Also, Picozzi et al. [20] reported that $64.7 \%$ of ears treated with topical gentamycin-hydrocortisone and self-mopping versus $21.4 \%$ of ears treated with topical placebo and self-mopping became dry. Wilde et al. [21] observed good resolution rates in both groups of a clinical trial that compared packing the ear with wicks impregnated with tetracycline-colistin versus filling the ear with ointment without wicks.

In mass treatment of school children with discharging ear in Zaire, Mahoney [22] noted a $70 \%-80 \%$ disappearance of otorrhea using ear wicks impregnated with alum acetate. The wicks were changed daily. With plain gauze ribbons, the wicking action stops once they are soaked with ear discharge [16] The Integrated Management of Childhood Illness (IMCI) guidelines recommend daily changing of the wicks to prevent maceration of infected moist material [16]. But, none of these studies addressed the period of ceasation of ear discharge as an important or key issue from the day of first presentation.

In sub-Saharan Africa with low economic activities, poverty and lack of access to health facilities, inadequate treatment of this disease may lead to chronicity, which is the reason why most cases of CSOM are emerging. In this study, ceasation of ear discharge was significant when aural toileting and dressing with gauze impregnated 
with antibiotic was carried out. Ceasation of ear discharge within 48 hours helps in non-progression to chronic state called CSOM.

Aural toileting reduces the source of infection which is located in the purulent discharge. It also allows instillation of antibiotic through the antibiotic-impregnated gauze which passes through the perforated tympanic membrane to the middle ear. The dressing also mops any residual discharge. The aural dressing must not necessarily be done by only a Physician, but also by a Nurse and primary health worker if adequately trained.

Ceasation of otorrhea is a most desirable measure in acute suppurative otitis media to prevent progression to chronic suppurative otitis media. Therefore, aural toileting through suctioning (either electronic or manual) should be encouraged, followed by ear dressing at first visit and repeated until there is ceasation of ear discharge. It should be done gently without injury to the external auditory canal and also to the perforated tympanic membrane. Ceasation of otorrhea reduces onset of complications in both ASOM and CSOM. However, systemic oral antibiotic treatment must be continued for 10 - 14 days despite the ceasation of ear discharge for complete eradication of the disease followed by aggressive measures to prevent upper respiratory tract infections for the next 3 months. This aids in complete healing and sealing of the tympanic membrane perforation.

On the basis of this study, our centre adopted this guideline of mandatory aural toileting (suctioning and moping with gauze soaked in $\mathrm{H}_{2} \mathrm{O}_{2}$ or methylated spirit) before dressing with gauze impregnated with topical antibiotic (ofloxacin or otomed). This line of management has also completely stopped progression to CSOM for patients who faithfully followed up this management with 14 days antibiotic treatment, and aggressive preventive measures of upper respiratory tract infections for 3 months which were given as advice to the patients and their relatives. Aural suction toileting and dressing for ASOM is simple to carry out and it is safe in all age groups. The ear must be kept dry (avoidance of water entering in) until the completion of antibiotic treatment. This encourages the healing and formation of neomembrane.

Upper respiratory infection must be prevented or actively treated (if it occurs) in the next 3 months to ensure the healed perforated tympanic membrane is strong enough to withstand further assault.

\section{Recommendations}

1) Aural toileting involving suctioning (electric or manual) or moping and ear dressing is a simple and safe method.

2) To reduce the incidence of progression to CSOM, it is advised that it should be done on the first visit of out-patient Otolaryngological clinic, Paediatrician clinic or Primary health centre.

3) When there is ceasation of ear discharge, usually within 48 hours, ear must be kept dry from water until the completion of oral antibiotic medication to the sensitive organism for 10 - 14 days.

4) Upper respiratory tract infection must be prevented actively for the next 3 months for the uninterrupted healing of the tympanic membrane.

5) Any upper respiratory tract infection in future must be treated actively, whether bacterial or viral.

6) By implication, CSOM may be treated by the same way from the first day of clinic visit after ear swab for $\mathrm{m} / \mathrm{c} / \mathrm{s}$ might have been taken.

7) This can be carried out even in primary health centres, secondary health centres just to achieve the main goal of preventing CSOM which is a major disease burden.

8) In the absence of suction toileting, syringes/canula can be used to aspirate purulent discharge from the external auditory canal to reduce the disease burden.

\section{Conclusion}

Aural ear toileting and dressing appear to show significant contribution to the early ceasation of ear discharge and are highly recommended not only for acute suppurative otitis media but also for all suppurative ear diseases.

\section{References}

[1] Taylor, S., Marchisio, P., Vergison, A., et al. (2012) Impact of Pneumococcal Conjugate Vaccination on Otitis Media: A Systemic Review. Clinical Infectious Diseases, 54, 1765-1773. http://dx.doi.org/10.1093/cid/cis292

[2] Cherpillod, J. (2011) Acute Otitis Media in Children. International Journal of General Medicine, 4, 421-423. http://dx.doi.org/10.2147/IJGM.S10309

[3] Okafor, B.C. (1984) The Chronic Discharging Ear in Nigeria. The Journal of Laryngology Otology, 98, 113-119. 
http://dx.doi.org/10.1017/S0022215100146298

[4] Lasisi, A.O., Sulaiman, O.A. and Afolabi, O.A. (2007) Socio-Economic Status and Hearing Loss in Chronic Suppurative Otitis Media in Nigeria. Annals of Tropical Paediatrics, 27, 291-296. http://dx.doi.org/10.1179/146532807X245689

[5] Brobby, G.W. (1992) The Discharging Ear in the Tropics: A Guide to Diagnosis and Management in the District Hospital. Tropical Doctor, 22, 10-13.

[6] Rea, P. and Graham, J. (2008) Acute Otitis Media in Children. In: Clarke, R., Ed., Scott-Brown's Otorhinolaryngology, Head and Neck Surgery, 7th Edition, Vol. 1, CRC Press, London, 912-925. http://dx.doi.org/10.1201/b15118-86

[7] Iseh, K.R. and Adegbite, T. (2004) Pattern of Bacteriology of Acute Suppurative Otitis Media in Sokoto, Nigeria. Annals of African Medicine, 3, 164-166.

[8] Rovers, M.M., Schilder, A.G., Zielhuis, G.A. and Rosenfeld, R.M. (2004) Otitis Media. Lancet, 363, 465-473. http://dx.doi.org/10.1016/S0140-6736(04)15495-0

[9] Browning, G.G. (1997) Aetiopathology of Inflammatory Conditions of the External and Middle Ear. In: Booth, J.B., Ed., Scott-Brown's Otolaryngology, Butterworths, London, 3/3/7-18.

[10] Canter, R.J. (1997) Acute Suppurative Otitis Media. In: Booth, J.B., Ed., Scott-Brown’s Otolaryngology, Butterworths, London, 3/9/1-7.

[11] McCracken Jr., G.H. (2002) Diagnosis and Management of Acute Otitis Media in the Urgent Care Setting. Annals of Emergency Medicine, 39, 413-421. http://dx.doi.org/10.1067/mem.2002.122772

[12] Rothman, R., Owens, T. and Simel, D.L. (2003) Does This Child Have Acute Otitis Media? The Journal of the American Medical Association, 290, 1633-1640. http://dx.doi.org/10.1001/jama.290.12.1633

[13] Gupta, S.C., Sharia, V.K., Effiong, C.E., Purik, B. and Srivastera, G. (1983) Bacteriology of Acute Otitis Media in Children. Nigerian Journal of Paediatrics, 10, 113-116.

[14] Nwawolo, C.C., Odusanya, O.O., Ezeanolue, B.C. and da Liiy-Tariah, O.B. (2001) Clinical Profile of Acute Otitis Media among Nigerian Children. West African Journal of Medicine, 20, 187-190.

[15] Brobby, G.W. and Zadik, P. (1987) Bacteriology of Otitis Media in Ghana. Tropical Doctor, 17, 19-22.

[16] WHO Library Cataloguing-in-Publication Data (2004) Chronic Suppurative Otitis Media: Burden of Illness and Management Options. World Health Organisation, Geneva.

[17] (1996) Prevention of Hearing Impairment from Chronic Otitis Media. Report of a WHO/CIBA, Foundation Workshop, London, 19-21.

[18] Ludman, H. (1980) Discharge from the Ear: Otitis Externa and Acute Otitis Media. British Medical Journal, 281, 1616-1617. http://dx.doi.org/10.1136/bmj.281.6255.1616

[19] Eason, R., Harding, F., Nicholson, R., Nicholson, D., Pada, J. and Gathercole, J. (1986) Chronic Suppurativeotitis Media in the Solomon Islands: A Prospective Microbiological, Audiometric and Therapeutic Survey. The New Zealand Medical Journal, 22, 955-966.

[20] Piccozi, G., Browning, G. and Galder, I. (1983) Controlled Trial of Gentamycin and Hydrocortisone Ear Drops in the Treatment of Active Chronic Otitis Media. Clinical Otolaryngology, 8, 367-368.

[21] Wilde, A.D., England, J. and Jones, A.S. (1995) An Alternative to Regular Dressings for Otitis Externa and Chronic Otitis Media? The Journal of Laryngology Otology, 109, 101-103. http://dx.doi.org/10.1017/S0022215100129391

[22] Mahoney, J.L. (1980) Mass Management of Otitis Media in Zaire. Laryngoscope, 90, 1200-1208. http://dx.doi.org/10.1288/00005537-198007000-00016 
Scientific Research Publishing (SCIRP) is one of the largest Open Access journal publishers. It is currently publishing more than 200 open access, online, peer-reviewed journals covering a wide range of academic disciplines. SCIRP serves the worldwide academic communities and contributes to the progress and application of science with its publication.

Other selected journals from SCIRP are listed as below. Submit your manuscript to us via either submit@scirp.org or Online Submission Portal.
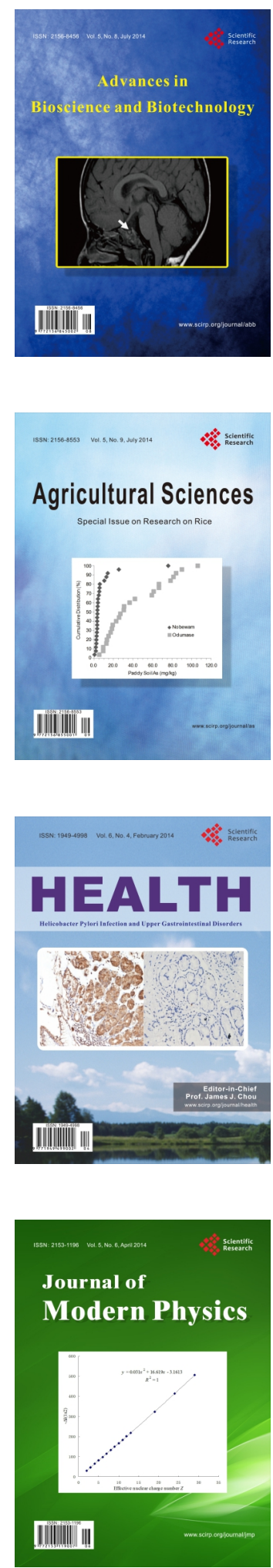
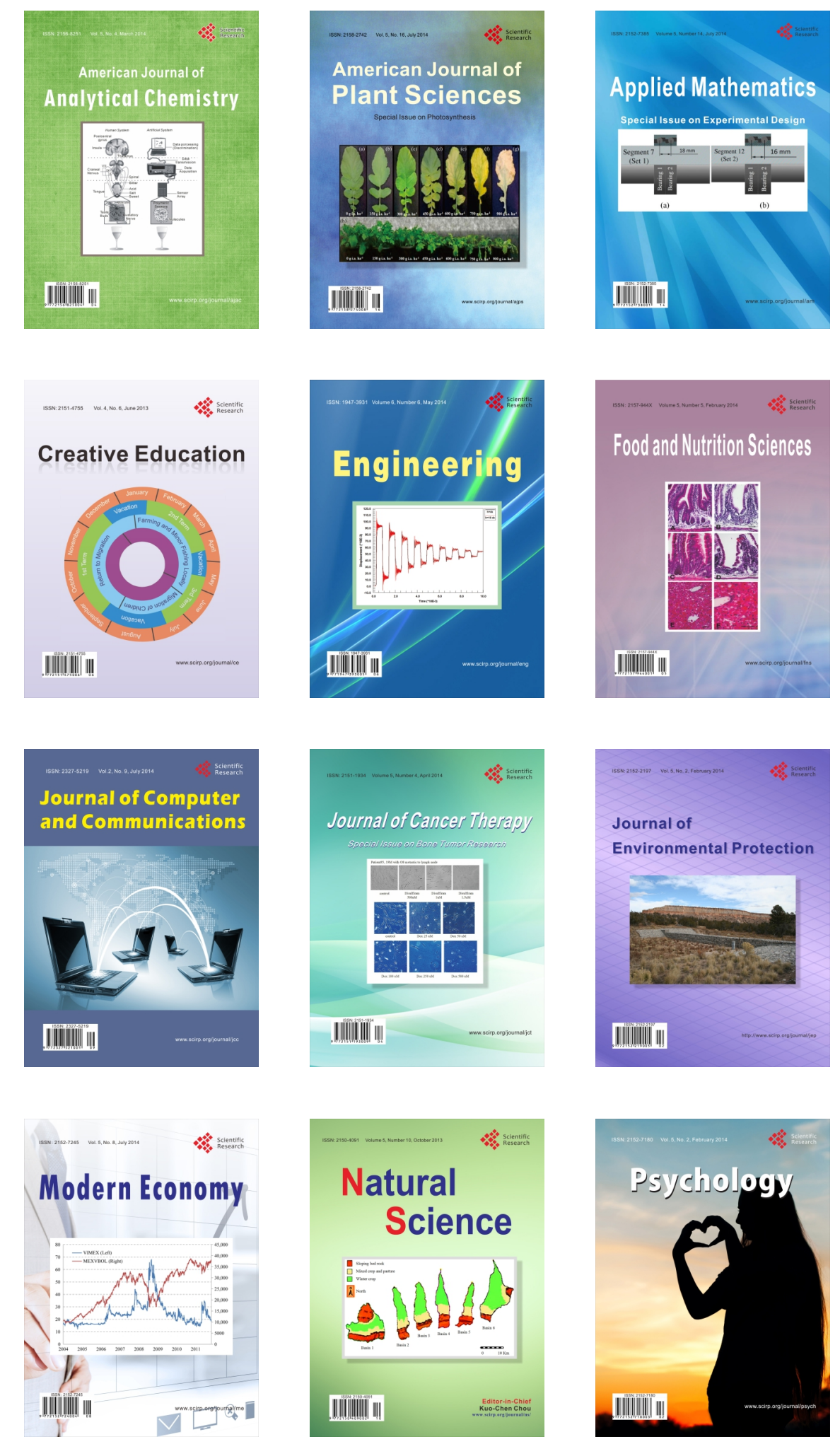